\title{
Russell on Denoting and Language
}

Link to publication record in Manchester Research Explorer

\section{Citation for published version (APA):}

Stevens, G. (2018). Russell on Denoting and Language. In R. Wahl (Ed.), The Bloomsbury Companion to Bertrand Russell Bloomsbury Publishing PLC.

\section{Published in:}

The Bloomsbury Companion to Bertrand Russell

\section{Citing this paper}

Please note that where the full-text provided on Manchester Research Explorer is the Author Accepted Manuscript or Proof version this may differ from the final Published version. If citing, it is advised that you check and use the publisher's definitive version.

\section{General rights}

Copyright and moral rights for the publications made accessible in the Research Explorer are retained by the authors and/or other copyright owners and it is a condition of accessing publications that users recognise and abide by the legal requirements associated with these rights.

\section{Takedown policy}

If you believe that this document breaches copyright please refer to the University of Manchester's Takedown Procedures [http://man.ac.uk/04Y6Bo] or contact uml.scholarlycommunications@manchester.ac.uk providing relevant details, so we can investigate your claim.

\section{OPEN ACCESS}


Please do not cite this version. The published version is:

The Bloomsbury Companion to Bertrand Russell

Ed. Russell Wahl, London: Bloomsbury, 2019, pp. 179-204.

\section{Russell on Denoting and Language}

Graham Stevens, University of Manchester

Introduction

Many people would credit Russell as the founder of analytical philosophy. Even those who express reservations about conferring that accolade on him will agree that his theory of descriptions, published in 1905's 'On Denoting' marks a pivotal moment in the establishment of analytical philosophy as we now know it. This is largely down to the enormous influence of that work on establishing analytical philosophy of language as a core element of modern philosophy. Yet, according to the majority of recent commentators, Russell had no more than a fleeting interest in the philosophy of language. Russell's greatest philosophical legacy, on this view, was accidental. In this chapter, I will challenge this interpretation and offer in its place a radical reappraisal of the theory of descriptions and its place in Russell's philosophy, arguing that it was always intended to be part of a wider project in the philosophy of language. That project places the analysis of propositional content at the very heart of philosophy. This, I argue, was Russell's primary concern throughout his entire work, and the theory of descriptions was a crucial component of it. This is not to say that the many applications of the theory of descriptions to other areas such as epistemology and ontology were 
not also of central importance to the theory, but I will argue that these applications actually rely on the premise that the theory of descriptions is a theory of natural language semantics and thus serve to demonstrate the fundamental role played by the philosophy of language as the foundation for Russell's philosophical project as a whole. As I will go on to show, there are some aspects of the theory which Russell prized highly that do pose an obstacle to the continued application of the theory to contemporary philosophy of language. However, I will argue that these aspects of the theory are expendable and that the theory of descriptions can, and should, be exorcised of them.

\section{Russellian Propositions}

In his book on Leibniz, written very early on in his philosophical career, Russell provided a clear statement of his approach to philosophical analysis that perfectly captured the key element that would drive his philosophical thinking for the next half century: 'That all sound philosophy should begin with an analysis of propositions, is a truth too evident, perhaps, to demand proof' (Russell, PL: 8). True to his word, Russell's philosophy always reserved a central position for the analysis of propositional content, even in those periods where he sought to deny the reality of propositions.

Russell's first theory of propositions remains one of his greatest legacies. Russellian propositions, as we now call the entities he posited in the semantic theory underwriting 1903's Principles of Mathematics, are mind and language independent objects composed of the very things that our words and thoughts are about. The proposition that Socrates is mortal, for example, is an object whose constituents include the individual Socrates and the property of mortality ${ }^{1}$. The proposition is both the meaning of the declarative sentence

\footnotetext{
${ }^{1}$ Whether the proposition contains any other constituents proved to be a difficult question for Russell to answer, as he grappled with the question of whether some extra entity or collection of entities is required to unify Socrates and mortality into the proposition that Socrates is mortality (see Stevens 2005 for extended discussion).
} 
"Socrates is mortal", and the object of various "propositional attitudes" towards it such as the belief, wish, hope, or fear, that Socrates is mortal.

This semantic theory, Russellianism, has a number of highly desirable attributes that continue to make it appealing to contemporary philosophers of language. ${ }^{2}$ For one thing, it has the virtue of simplicity and elegance - meaning is a very simple sort of a thing on Russell's theory: words stand for simple entities which are their meanings, and sentences composed from those words stand for complex entities composed of the simple entities. Furthermore, Russell's key intuition here that (at least some) words stand directly for objects (i.e. the intuition that for many expressions meaning is no more than reference) resonates powerfully with more recent arguments for a direct-reference semantic theory for certain core expressions including proper names, indexicals and demonstratives. However, despite these attractions, the theory has been plagued by difficulties since its inception. The difficulties divide roughly into metaphysical problems and semantic ones. The most pressing metaphysical problem is the problem of the unity of the proposition. The problem of the unity of the proposition is the problem of how to explain the difference between a proposition and the mere collection of its constituents. Propositions have a distinctive kind of unity that is quite different to the unity had by objects like sets, and unless Russell can explain what that unity consists in, it seems as if the simplicity of his semantics is bought only at the expense of metaphysical mystery. I will not pursue the metaphysical problems here, as the focus of this chapter is Russell's semantic theory. ${ }^{3}$

The semantic problems besetting Russellianism stem from Russell's insistence that propositions are composed of the objects they are about, as opposed to representations of those objects. This yields two fundamental kinds of difficulty. Firstly, it becomes hard to explain how talk of non-existent things can be meaningful; secondly, the theory faces a cluster of challenges revolving around its counter-intuitive predictions about certain apparently intensional contexts. An intensional sentence is distinguished from an extensional sentence

${ }^{2}$ See, e.g. Kaplan 1989, Kripke 1980 Salmon 1986, King 2007, among many others.

3 I have pursued it in detail in several other places, including Stevens 2003, 2004, 2005, 2008. 
by the fact that some aspect of meaning distinct from reference of some or all of the (referring) expressions in the sentence appear to be significant in fixing its truth-conditions, whereas only the reference of its (referring) expressions is significant to a sentence's truth-conditions in an extensional context. But, as noted above, Russell's theory effectively eschews any notion of meaning distinct from reference. This, obviously, will make intensional contexts problematic for the Russellian. Consider the following two examples:

a. The morning star and evening star are both the same object, namely the planet Venus, seen at different times of the day. If we assume that the expressions "the morning star" and "the evening star" simply have the object Venus as their semantic values, then the following two sentences mean the same thing (express the same Russellian proposition):

i. The morning star is the evening star.

ii. Venus is Venus

Yet, intuitively, (i) is an informative identity statement, whereas (ii)is trivial.

b. Assume that the Superman fiction is true. Then, Lois believes that Superman can fly. Superman is Clark Kent. If the meanings of the names "Superman" and "Clark Kent" are simply the individuals they refer to, then, as they refer to the same individual, the two names must contribute the same individual to the proposition expressed by any sentence using these names. In which case, the sentences "Superman can fly" and "Clark Kent can fly" express the same proposition. So Lois must believe that Clark Kent flies. Yet, intuitively, Lois does not believe this.

Problems such as these had led Frege to adopt a more complicated semantic theory, Fregeanism, which divides semantic content into two distinct levels, which he termed the sense and reference of an expression. The sense is a mode of presentation of the referent. The difference in sense between the two expressions in the pairs "evening star, morning star" and "Clark Kent, Superman" are appealed to by Frege in explaining the above examples. In the case of (a) the sentence (i) is informative because it identifies two different modes of 
presentation as being modes of presentation of the same object, whereas (ii) identifies the same object by the same sense, hence it is trivial. ${ }^{4}$

These two competing semantic theories offer competing ontological accounts of what sorts of things propositions are. Russellianism treats propositions as composed of the individuals they are about; Fregeanism treats propositions as composed of representations of the individuals they are about. To a great extent, the choice between these two positions has defined discussions of the nature of propositional content ever since, at least for those who take propositions to be structured entities. ${ }^{5}$

Russell's response to the semantic problems can easily be mistaken for just another version of Fregeanism. ${ }^{6}$ However, this would be to seriously misunderstand Russell's position. Russell's response comes in two parts, only one part of which retains its appeal to this day. The first part, and the one which is still popular, is his theory of descriptions. This theory, which I will explain in detail in the next section, treats definite descriptions as devices of quantification, not reference. The second part, which is now almost universally rejected by philosophers of language, argues that proper names are disguised definite descriptions. Thus, while their grammatical form makes them appear like simple referring expressions, they are in fact quantificational expressions which have no referential function. It is tempting to gloss this as a version of Fregeanism as it also responds to the semantic problems by denying that the expressions in question contribute objects (referents) to the propositions they are being used to

\footnotetext{
${ }^{4}$ An additional semantic problem arises when we consider what semantic value "empty" names like "Bilbo Baggins" or "Pegasus" have. This is a separate problem which I shall not consider here (see Stevens 2011 for discussion), hence our assumption that the Superman fiction is true in the above example.

${ }^{5}$ Alternative, unstructured, accounts of propositions usually take them to be identified with sets of worlds at which they are true.

${ }^{6}$ A third theory, which we will not consider here, was proposed in Russell's (1903). This theory has some similarities with both Fregeanism and Russellianism, but is importantly distinct from either. Denoting phrases, on this theory, express denoting concepts which have often been construed as akin to Fregean senses, however the theory (like Russell's later 1905 theory) treats denoting phrases as quantifier phrases (though his analysis of quantification is quite different to that provided by the later theory). Russell himself helps to confuse things by describing his 1903 theory as 'very nearly the same as Frege's' (Russell 1905: 42) when presenting his later alternative.
} 
express. However, there are some fundamental differences that should not be overlooked.

Firstly, Russell is insistent that definite descriptions do not have any representational meanings akin to a Fregean sense. Indeed he goes to great lengths when introducing the theory to argue that the Fregean distinction between sense and reference is unworkable and offers the theory of descriptions in its place. Furthermore, the recent publication of his manuscripts from the period in which he devised the theory of descriptions show clearly that the theory arose in part out of his criticisms of Frege's theory, not in response to the semantic problems. Russell repeatedly insists that definite descriptions are 'incomplete symbols' which have no meaning at all in isolation.

Secondly, Russell is modifying, but not rejecting, Russellianism. Although he is recognizing that not all propositions are as simple as the original version of Russellianism presented them as being, he is maintaining the core thesis of Russellianism that propositions contain the things they are about. However, he no longer thinks that sentence of the form "The F is G" are about the F. Rather he thinks, as we shall see in the next section, that they have on analysis a more complicated structure that reveals the propositions they express to be more complex also. Furthermore, despite his insistence that proper names are not devices of reference (and hence that the proposition that Socrates is mortal does not contain Socrates), he still maintains that Russellianism is strictly speaking correct, in the sense that every genuine device of reference will contribute its referent as its semantic value. He simply draws a distinction between logically proper names and grammatically proper names. The grammatically proper names "Socrates" is not a logically proper name. Other expressions, however, such as demonstrative pronouns, are still taken to be logically proper names and these receive the same treatment as in earlier versions of the theory.

Thirdly, Russell's quantificational analysis of descriptions is quite different to Frege's claim that descriptions have a sense. We might helpfully think of the situation as follows. The presence of obviously quantificational expressions like 'all', 'every', 'no', etc. in English already demonstrates the need to recognize expressions that do more than just refer directly to objects. Both Frege and Russell do so by introducing a syntactic theory of quantification. By 
extending the treatment of quantifiers to embrace definite descriptions, Russell is attempting to explain the semantic puzzles by appeal to this syntactic mechanism rather than by appeal to an additional semantic mechanism like the sense/reference distinction.

\section{Russell's Theory of Descriptions}

According to Russell's 1905 theory of descriptions, the grammatical similarity between definite descriptions and referring singular terms is an illusory accident of English (and, presumably, many other natural languages, although Russell never really address this question). The situation, as mentioned above, is somewhat complicated by Russell's additional claim that many of the expressions we would think of as paradigmatic referring expressions, such as proper names, are what he calls "disguised" descriptions. It will help to elucidate Russell's position if we overlook this additional thesis momentarily. Consider these two sentences:

(a) David Cameron is dishonest

(b) The present Prime Minister of the United Kingdom is dishonest

Grammatically, both sentences seem to combine a noun phrase with a predicate expression. So they seem to share the same syntax. This might naturally lead us to expect a shared semantic structure also. However, Russell's theory takes the surface grammar of English to conceal the true structure of the propositions these sentences express. The correct logical forms (i.e. the structures of the proposition each sentence expresses) are radically different, and can be paraphrased as follows:

(LFa) David Cameron is dishonest

(LFb) There is one and only one $x$ such that $x$ is presently Prime Minister of the United Kingdom and $x$ is dishonest. 
The definite description, in other words, has a very different semantic function to the name, despite the fact that both appear to be used to talk about the same person. The name introduces that person directly into a proposition, whereas the definite description introduces into a proposition a uniquely quantifying concept that picks out that person.

The analysis of definite descriptions is just one part of the theory of descriptions developed by Russell in 1905. The complete theory is a general theory of quantification that locates definite descriptions within the class of firstorder quantifiers along with expression like "all Fs", "every F", "no F", "some F(s)", "not all Fs", and indefinite descriptions like "an F". The publication of the first volume of Principia Mathematica in 1910 effectively established as orthodoxy the view that the meanings of these expressions can be captured within first-order predicate logic, and their translation into that language is now standard fare for all students of the predicate calculus. The orthodoxy nonetheless has not gone unchallenged, and the inclusion of definite descriptions on this list of quantifier expression has been by far the most controversial claim. Perhaps its fiercest and most influential challenge came from Strawson (1950). Strawson's general objection was summarized by his insistence that 'ordinary language has no exact logic' (1950: 27), an objection grounded in a series of more local objections to the theory of descriptions.

Strawson objected to the theory of descriptions on both a negative and a positive front. The negative point consists in a famous problem that he raised for the theory called the problem of incompleteness. The positive point consists in his alternative proposal about the functioning of definite descriptions which draws extensively on pragmatics rather than semantics and which, he maintains, provides more reliable predictions concerning the behavior of "empty" descriptions like 'the present king of France". Both points have been highly influential and continue to be the focus of discussion to date.

The problem of incompleteness arises because it seems that everyday uses of definite descriptions are far more relaxed with regard to the uniqueness of the thing described than Russell's theory appears to predict. For example, it is perfectly natural to say things like "the book is over there" in a context where the speaker is communicating the location of a particular book. But Russell's theory 
analyses this utterance as encoding the proposition that one and only one thing is a book and that that thing is in the demonstrated location. In all worlds, including the actual world, containing more than one book, this proposition is false. Yet, intuitively, the utterance has communicated something true. This must mean, so the objection runs, that Russell is wrong about which proposition is encoded by the utterance.

The problem of incompleteness is best countered by the observation that it can be viewed as an instance of the general natural language phenomenon of contextually mandated quantifier restriction. All natural language quantifiers are subject to restriction within context to a narrowed range of variables. For example, when I am asked how my lecture on the theory of descriptions went, I might reply "everyone was bored", but here it is obvious that the range of the quantifier "everyone" has been restricted to a contextually salient class of people (those who were present at the lecture). Close inspection reveals that such contextual restriction of quantification is routine in natural language. Competing semantic and pragmatic explanations of how exactly this phenomenon functions can be given, but the only point that really matters here is that, if we take the problem of incompleteness to be an instance of this general phenomenon, then definite descriptions are clustering with quantifier phrases more generally. Thus, viewed in this way, the problem of incompleteness is turned on its head, becoming evidence for, rather than against, Russell's quantificational analysis of definite descriptions.

Strawson's positive proposal is usually seen as a contribution to pragmatics. Strawson argues that uses of definite descriptions introduce a 'presupposition' of reference to contexts in which they feature. For example, interpretation of the sentence 'the present CEO of Google stole my wallet' requires the presupposition that there is a present CEO of Google. Without this presupposition it is not clear that the sentence even expresses a proposition at all. Certainly, according to Strawson, it fails to express anything holding a truthvalue. Thus, in cases of sentences displaying reference failure, such as we encounter with sentences like 'the present king of France is bald', Strawson predicts that the sentences will lack a truth-value. In fact, intuitions appear to diverge quite wildly with respect to this example. Some hear the sentence as 
straightforwardly false (as Russell predicts), whereas others find it odd to attribute a truth-value to the sentence (as Strawson predicts). Nonetheless, there are other cases where intuition does not seem to be on Strawson's side at all. Stephen Neale (1990) points out that competent English speakers who know that France lacks a monarchy are in almost universal agreement regarding many utterances of sentences about the present king of France. Certainly, the current students on my Russell course at Manchester were in universal agreement that my claim that "I had dinner with the present king of France last night" is straightforwardly false when I tested this slight modification of Neale's example out in a recent lecture. Hence, it seems, that the question of whether all uses of definite descriptions presuppose reference is harder to answer than Strawson thought. Regardless of whether his proposal should depose Russell's quantificational analysis, however, there can be no doubt that Strawson's work has revolutionized pragmatic theory, which has developed the theory of presupposition to areas far beyond the domain of definite descriptions.

To a large extent, Strawson and Russell can be understood as championing the referential and the quantificational interpretations of descriptions respectively. The next great development in the debate came with Donnellan's (1966) argument that both Strawson and Russell were partially correct and, at the same time, partially incorrect. Donnellan provided a series of examples demonstrating both referential and quantificational (or, as he termed them, attributive) functions.

Imagine a case where detectives are called to the scene of a suspected murder. The body of Smith is found brutally butchered. Confronted by what appears to be an attack of extreme violence, one of the detectives says "Smith's murder is insane". This is an attributive use of the description "Smith's murderer". No particular object is in the detectives mind when uttering the sentence. Rather the detective means something like "whoever it was that did this must be insane". Next consider a case where a suspect has been arrested on suspicion of the murder and is being questioned in court. The suspect acts extremely unpredictably in the courtroom, talking to themelves, responding to questions with bizarre answers, and so forth. Someone in the courtroom watching this display whispers to the person next to them "Smith's murderer is 
insane". This is a referential use. What the speaker means is something like "that person over there is insane". Indeed, they will have successfully communicated this information even if the person in question does not answer to the description (e.g. if they have been wrongfully accused of the murder). In each of these cases the Strawsonian and Russellian analyses make differing truthconditional predictions about the content of the utterances. The Strawsonian correctly captures the truth-conditions of the referential use; The Russellian captures those of the quantificational/attributive use. Following Kripke's influential (1977) response to Donnellan, debate has centred (inconclusively) around whether one or the other of these analyses should be given priority as the correct account of the literal meaning of the utterance, while the other account is accommodated within a pragmatic explanation of non-literal uses of the sentences in question.

\section{Logical Form, Metaphysics and Semantics.}

Few debates have received as much attention in the philosophy of language as that instigated by Russell's theory of descriptions. Yet, somewhat surprisingly, it is common among scholars of Russell's philosophy to view this debate as no more than an accidental outcome of the theory. Russell himself, it is commonly claimed, was no philosopher of language and neither was the theory intended to bear on issues in the semantics of natural languages.

Certainly when one looks at both the context in which Russell discovered the theory, and the ingenious applications he immediately put the theory to after its discovery, it appears that natural language semantics was not Russell's primary concern. The theory was discovered and developed in response to the problems facing Russell's logicist project. In particular, the theory played a crucial role in the philosophical explanation of the theory of logical types which was intended to preserve the formal system of Whitehead and Russell's Principia Mathematica from the paradoxes of naïve set theory, most notably Russell's own paradox of the class of all classes which are not members of themselves. 
On April 14, 1904, Russell wrote to his first wife that he and Whitehead "had a happy hour yesterday when we thought the present King of France had solved the Contradiction; but it turned finally out that the royal intellect was not quite up to that standard. However, we made a distinct advantance" (Russell 1992: 277). Comments like this make it fairly plain that, right from the outset, Russell's interest in descriptions stemmed from his ongoing battles against the contradictions. He later wrote that the theory of descriptions was 'the first step towards overcoming the difficulties that had baffled me for so long" (Russell Auto 2: 152). The way that the theory helped was through the introduction of an analysis that allowed apparent logical subjects to be treated as incomplete symbols', showing that apparent reference to an entity (e.g. a class) could be explained without any ontological commitment to that object. This was crucial to the no-classes theory underlying the theory of types in Principia. ${ }^{7}$

Russell's own aims for the theory of descriptions then were clearly directed at concerns in logic and metaphysics. But it would be a mistake to conclude form this that the theory was not intended to make a contribution to the semantic analysis of natural language definite descriptions. Russell often (particularly after 1905) talks of natural language being defective or deficient, urging its replacement with what he calls a 'logically perfect language' (Russell 1918: 198), leading to his widespread characterization as the founder of socalled "Ideal Language Philosophy". There are, I think, at least two ways in which this term is used. On the first interpretation of ideal language philosophy (IP1), natural languages are viewed as deficient in the sense that they simply represent the world in an inaccurate way. So, for example, English uses expressions which have exactly the same linguistic form as referring expressions when in fact reality does not contain any objects for those expressions to refer to. Thus, English misrepresents how things really are. It would be better, according to IP1, to abandon English (at least within certain domains which strive for an accurate representation of reality, such as precise philosophy) and replace it with a logically perfect language which did not misrepresent reality in this way. Notice that IP1 does not simply urge an alternative grammar to replace that of the natural language in question, but also urges the adoption of an alternative

\footnotetext{
7 This is a point I will return to in detail below.
} 
semantics or, more precisely, urges the adoption of a language with a fundamentally different grammar and semantics. An example of a philosopher who defends IP1 would be Quine. Quine's proposal that all names should be converted into predicates ${ }^{8}$ and then uniquely quantified over so as to reveal our ontological commitments through our existentially quantified commitments is an attempt to replace natural language with something else. It is not in any way intended to be a thesis about the meanings of natural language names, indeed it is intended on the contrary to urge a wholesale revision of those meanings - a self-conscious adoption of an alternative semantics, rather than a statement of the original semantics.

On the second interpretation of Ideal Language Philosophy (IP2), what logical analysis does is to reveal a semantic structure which is superficially disguised by natural language. So, for example, English grammar seems to treat all noun-phrases as having the same function. But, in fact, the noun phrase "a man" has a very different semantic function to the proper name "Socrates" when combined with the verb-phrase "drank poison". A logically perfect language will remove the disguise and unveil the true structure and semantic function of natural language expressions. An example of a philosopher defending IP2 would be Frege, whose development of predicate logic is, among other things, designed to reveal the difference in semantic function (or, as he would call it, logical form) of these sorts of expressions. Evidently, the defender of IP2 cannot maintain a position of neutrality on issues in the philosophy of language in the way that the defender of IP1 can. Despite maintaining the logico-semantic deficiency of natural language, IP2 is a philosophical claim about natural language. Which variety of ideal language philosophy, then, is Russell defending?

There are two clearly distinct positions here. However, these were certainly not disambiguated by either Russell or his contemporaries and Russell slides quite ambivalently between the two. For example, Russell leans strongly towards IP1 when he explicitly warns against the dangers of expecting linguistic distinctions to mirror metaphysical ones in the chapter on "words and meaning" in The Analysis of Mind:

\footnotetext{
${ }^{8}$ Quine 1948.
} 
The things that words mean differ more than words do. There are different sorts of words, distinguished by the grammarians; and there are logical distinctions; which are connected to some extent, though not so closely as was formerly supposed, with the grammatical distinctions of parts of speech. It is easy, however, to be misled by grammar, particularly if all the languages we know belong to one family. In some languages, according to some authorities, the distinction of parts of speech does not exist; in many languages it is widely different from that to which we are accustomed in the Indo-European languages. These facts have to be borne in mind if we are to avoid giving metaphysical importance to mere accidents of our own speech.

(Russell, AMi: 191-2)

Elsewhere Russell diagnoses this same structural mismatch between language and reality as the source of the ancient question concerning the nature of relations (which, it should be noted, had been a constant source of puzzlement throughout Russell's own work in previous years):

There is however, a complication about language as a method of representing a system, namely that words which mean relations are not themselves relations, but just as substantial or unsubstantial as other words. In this respect a map, for instance, is superior to language, since the fact that one place is west of another is represented by the fact that the corresponding place on the map is to the left of the other; that is to say a relation is represented by a relation ... I believe that this simple fact is at the bottom of the hopeless muddle which has prevailed in all schools of philosophy as to the nature of relations.

(Russell 1923: 152-3)

Both of these passages are easily read as advocating something like IP1. However, it would be a mistake to ascribe the view to Russell as a universal philosophical attitude towards language. In particular, it would be wrong to interpret the theory of descriptions as part of this kind of project for two 
reasons: firstly, there is no compelling evidence in Russell's writing on the theory to support such a view, and plenty of evidence against it; secondly the theory of descriptions becomes largely incoherent if interpreted in this way. I will expand on each reason in turn.

Russell's justifications for the theory of descriptions repeatedly appeal to arguments about the semantic function of definite descriptions in natural language. His classic statement of the theory in 'On Denoting', for example, adopts the strategy of posing three puzzles which, he maintains, must be solved by any viable theory of denoting. All three puzzles are straightforwardly semantic puzzles - puzzles about the meanings of denoting phrases, or the sentences containing them, in natural language. The first puzzle is a version of Frege's puzzle concerning de dicto attitude reports involving expressions which denote the same object. This is simply a question about the semantics of propositional attitude reports involving denoting phrases. The second is the famous 'present king of France' case, and concerns the apparent failure of the law of excluded middle which occurs when a sentence of the form 'A is B' and its (apparent) negation 'A is not B' has an empty definite description like 'the present king of France' in place of ' $A$ '. This is simply a question about the truthconditions of English sentences with non-referring terms in subject position. The third puzzle also concerns the semantics of non-referring expressions: we can form a definite descriptions 'the difference between A and B' regardless of whether A and B actually differ. For example, if they do not differ then it is meaningful and true to say 'the difference between A and B does not exist'. Russell, due to other commitments in his semantic theory which are not clearly expounded in 'On Denoting', thinks that there is something very paradoxical about a proposition that denies the existence of its own subject. This may not be as familiar a case of a semantic concern to those unfamiliar with Russell's philosophy but it is a concern about semantics all the same.

The theory of descriptions is forwarded as providing a complete solution to all three puzzles. It solves the puzzle of de dicto attitude reports which differ in truth-value despite ascribing seemingly the same attitudes about the same objects, by analyzing the propositions in question into complex quantificational forms in which they turn out not to be about the same objects after all. George IV, 
in Russell's example, can wonder whether Scott is the author of Waverley without this collapsing into the trivial question of whether Scott is Scott because the proposition George actually stands in an attitude towards is the proposition that Scott is identical with one and only one thing which authored Waverley, whereas he does not stand in the same relation to the proposition that Scott is self-identical. ${ }^{9}$ This is clearly not any part of a defence of IP1. Russell is not arguing that English needs to be abandoned and replaced with a language with a different semantics, he is simply presenting an argument for ascribing a given semantic interpretation of part of English. The solution offered to the second puzzle is directly aimed at the semantic profile of the English sentence "The present king of France is not bald'. Russell's argument here is that the sentence, intuitively, has two readings:

(1) There is an entity which is presently king of France and it is not bald.

(2) It is false that there is an entity which is presently king of France and bald.

Russell's theory, we know, predicts this brilliantly as the quantificational form of the sentence it ascribes permits a syntactic interplay between the existential quantifier and the negation operator which gives reading (1) or (2) depending on which of these has wide scope over the other:

$$
\begin{aligned}
& \text { (1a) } \exists x((F x \&(\forall y)(F y \supset x=y)) \& \sim G x) \\
& (2 a) \sim \exists x((F x \&(\forall y)(F y \supset x=y)) \& G x)
\end{aligned}
$$

This is a paradigm instance of IP2, and a world away from IP1. Russell is directly appealing to the semantic behaviour of English sentences and to our intuitions qua English speakers about the truth-conditions of English sentences to argue for a given semantic interpretation of English definite descriptions.

\footnotetext{
${ }^{9}$ Russell actually confuses the example by using a demonstrative when explaining the wide scope reading, which he says 'would be true, for example, if George IV had seen Scott at a distance, and had asked "Is that Scott?"' (Russell 1905: 52; see Kripke 2005, Stevens 2011 for discussion).
} 
The third puzzle, concerning the formation of propositions seemingly about things which do not exist, is solved by the same mechanism of course - on the analyses given above, propositions about 'the $\mathrm{F}^{\prime}$ are not really about any entity after all, as a survey of their logical forms reveals. No expression referring to the present king of France can be found in (1a), for example. Again, we have a solution to the puzzle which relies on arguing for a certain semantic interpretation of the natural language expression in question. Another clear instance of IP2, in other words.

The above considerations give us overwhelming evidence for interpreting the theory of descriptions as a contribution to a project along the lines of IP2, not IP1 (regardless of whether other aspects of Russell's philosophy may be better interpreted as contributions to IP1). But there is an even stronger reason than this for situating the theory of descriptions within the framework of IP2, namely the theory is simply incompatible with IP1, as is made clear by considering the ways in which Russell appeals to the theory when applying it more widely within his philosophy.

Consider, by way of an example, Russell's application of the theory to provide a foundation for his epistemological distinction between knowledge by acquaintance and knowledge by description. The latter sort of knowledge allows us to have thoughts about objects that we are not acquainted with only because it is grounded in the theory of descriptions, according to which knowledge about such objects is accesses via certain concepts that they fall under (including the quantificational concept of uniqueness). It is crucial to this claim, however, that the theory of descriptions is a theory of the semantic content of natural language definite descriptions. The theory of descriptions is doing all of the hard work in this claim, and the epistemological thesis rides on the back of it. If definite descriptions were devices of direct reference in natural language, the proposal would not get off the ground at all. This is also why Russell's extension of the distinction to the use of names forces him to endorse the semantic claim that proper names really do have a descriptive content. The Quinean (IP1) position whereby we replace referring expressions with quantificational ones in order to reveal ontological commitments more clearly would not establish the 
epistemological claim that Russell endorses. ${ }^{10}$ Russell's position is that we cannot be acquainted with the objects seemingly referred to by most proper names, hence our understanding of those names must not be a matter of our apprehending those objects. The theory of descriptions explains how we can understanding them only if we take the extra semantic step of insisting that the contents of ordinary proper names are not objects at all, but that names have an entirely different, quantificational, function. The theory of descriptions is thus, at the most fundamental level, a theory of natural language semantics, and its role in Russell's philosophy even when it is applied to issues beyond those directly pertaining to semantics, remains firmly anchored in those semantic considerations.

\section{Going forward: two problems with the theory of descriptions}

Following on from the above discussion of the theory of descriptions as a theory of natural language semantics I now want to discuss two problems with the theory, which suggest, I think, a need for some modifications to Russell's theory if it is to remain a viable account of the semantics of natural language quantification. The first problematic feature of the theory is Russell's conflation of semantic and epistemological considerations. The second problematic feature is Russell's insistence that descriptions are 'incomplete symbols'.

\subsection{Semantics versus epistemology.}

The theory of descriptions is a semantic theory. Unfortunately however, Russell ran together semantic and epistemological considerations right from the very inception of the theory. This conflation of semantics and epistemology may very well have been present in his thinking before the discovery of the theory in 1905. Indeed, the best explanation for a number of passages in 1903's Principles of Mathematics, requires the assumption that Russell is implicitly appealing to an

10 This is precisely why Quine's strategy of paraphrasing proper names as definite descriptions is immune to Kripke's objections to descriptivism, as Kripke acknowkledges (Kripke 1980: 29). 
epistemological principle to justify his semantic theory of denoting concepts. ${ }^{11}$ The epistemological principle is made explicit, however, in 'On Denoting', where Russell commends the theory on the grounds that it preserves the principle:

Thus in every proposition that we can apprehend (i.e. not only those whose truth or falsehood we can judge of, but in all that we can think about), all the constituents are really entities with which we have immediate acquaintance.

(Russell 1905: 56)

This principle was later dubbed "Russell's Principle” by Gareth Evans, who interpreted it as follows:

In order to have a thought about a particular object, you must know which object it is about which you are thinking.

(Evans 1982: 74)

For Russell, this epistemological component was a core commitment of the theory of descriptions that he recognized immediately upon devising the theory:

This topic is very interesting in regard to theory of knowledge, because most things are only known to us by denoting concepts. Thus Jones = the person who inhabits Jones's body. We don't have acquaintance with Jones, but only with his sensible manifestations. Thus if we think we know propositions about Jones, this is not quite right; we only know propositional functions which he satisfies, unless indeed we are Jones. Thus there can be no such thing as affection for persons other than ourselves; it must be either their sensible manifestations or the concepts denoting them that we like. It cannot be the latter, for it would be absurd to say that we loved some of these and hated others. Denoted objects only

\footnotetext{
${ }^{11}$ For example, it explains how we can apprehend propositions about infinite collections without requiring us to have acquaintance with an infinite number of things (see Russell 1903: 349).
} 
known to us as denoted may be identified, without such great error as in other cases, with the sum of their predicates; for it is only their predicates that we know, and these (all or some of those we know) must be meant by us whenever we speak of such objects. But we can only know an object as denoted if we are acquainted with the denoting concept; thus immediate acquaintance with the constituents of the denoting concept is presupposed in what we may call denotative knowledge.

(Russell 1905a: 369)

This distinction between knowledge by acquaintance and knowledge by description may be a perfectly valid and important one in epistemology, but Russell's importation of the distinction into his semantic theory has a number of unfortunate consequences. For one thing, it makes the step towards a descriptive theory of proper names a natural one, for the same epistemological puzzles that are solved by appeal to the distinction in kinds of knowledge appear mirrored in the semantic puzzles discussed above. Consequently, Russell's theory of descriptions has been unjustly blended in the eyes of many of Russell's interpreters with a rather messy hybrid of the descriptive theory of names and the distinction between knowledge by acquaintance and knowledge by description. In doing so, they have only been following Russell's own lead. But regardless of whether Russell himself saw these three things as essentially interconnected, and regardless of any evaluation of these three things, it is a mistake for us to view the theory of descriptions as committed to either of these extraneous additions about names or knowledge. There are three distinct theories here, all of which are in fact entirely independent of one another:

1. The semantic theory that definite descriptions contribute quantificational, not referential, content to the propositions expressed by the sentences in which they feature.

2. The semantic theory that proper names have descriptive content.

3. The epistemological theory that knowledge of objects comes in two distinct varieties: (a) direct knowledge of (acquaintance with) objects; (b) indirect (descriptive) knowledge of objects. 
That these three are independent of one another is fairly evident: one could endorse (1) but not (2) (as, for example, Kripke does ${ }^{12}$ ); one could endorse (2) but not (1) (as, for example, Frege $\operatorname{did}^{13}$ ); one could endorse (3) without either (1) or (2) (as, arguably at least, Russell did in 1903).

Aside from the messy interpretation of his theory that Russell's conflation of these issues has resulted in, there is a more serious concern. There is good reason for doubting the truth of Russell's principle. David Kaplan gives the following vivid example as a demonstration that epistemological access to the things one is talking about is not a necessary condition for referring to them:

A kidnapped heiress, locked in the trunk of car, knowing neither the time nor where she is, may think 'It is quiet here now' and the indexicals will remain directly referential.

(Kaplan 1989: 536)

In Kaplan's example, we have a very clear case of the paradigm directly referential expressions, indexicals, successfully referring in the absence of Russell's epistemological criterion. This shows that it is as mistaken to import (3) into the theory of descriptions as it is to import (2) into it. The theory of descriptions (1) must be permanently severed from (2) and (3) if it is to make a worthwhile contribution to continued theorizing about natural language quantification. ${ }^{14}$

12 Kripke 1977; 1980.

13 Frege 1892.

${ }^{14}$ It might be thought that Kaplan's objection is better directed at Evans than Russell (Kaplan himself does not explicitly direct it at either, but simply takes it to show that no special epistemological access to an object is required in order to refer to it with an indexical). Evans effectively revises Russell's principle to include the criterion that we must have discriminatory knowledge of an object in order to have a thought, or grasp a proposition, about it. This is clearly lacking in Kaplan's example. But could Russell reply that the heiress is acquainted with the present moment but unaware of what time it is? Perhaps this sounds plausible for the temporal indexical 'now', but is she acquainted with the referent of 'here'? Surely not, for her thought that 'it is quiet here now' is about the location in which the car is parked, not the inside of the trunk in which she is secured, and it seems quite implausible to think that she is acquainted with that place. 


\subsection{Incomplete symbols}

Let is now turn to the second problem with Russell's theory that I mentioned above, namely his insistence that descriptions are incomplete symbols. This view is crucial to the ends that he has in mind for the theory of descriptions, most notably it is this aspect of the theory which connects with the theory of types.

Russell's theory of types was, for many years, understood as heralding a fundamental change of heart on the part of its author about the nature of logic and of the interplay between logic and metaphysics. Russell's original version of logicism was grounded in simple metaphysics where all objects stood on a logical par. Russell endorsed a position which has been called "the doctrine of the unrestricted variable", according to which the variables of pure logic range over all things without any division of those things into distinct logical categories. Logic, on this view, is independent of any metaphysical assumptions about the nature of entities (though, of course, it may not be independent of metaphysical assumptions about which, or how many, entities there are). The theory of types appears to be a straightforward rejection of this position, as it restricts the range of a variable in accordance with type indexes. In recent years, however, the discovery and publication of Russell's manuscripts during the period in which he developed the theory of types has shown that this interpretation is, at best, overly simplistic. ${ }^{15}$ For at least some of the time during which Russell was developing the theory of types, he was intending to do so in a way which allowed him to maintain the doctrine of the unrestricted variable. The key to this was his "substitutional theory of classes and relations", developed during the period 1905-1907, but eventually abandoned before the completion of Principia Mathematica. The substitutional theory provides the missing link between Russell's theory of descriptions and his theory of types, making sense of his later claim, cited above, that it was the discovery of the former which held the key to the latter. The theory makes it very clear that the key feature of the theory of descriptions which paved the way for the theory of types was the notion of an incomplete symbol.

15 These manuscripts have now been published in CPBR 5. 
By an 'incomplete symbol', Russell is best understood ${ }^{16}$ as meaning a linguistic symbol which has no meaning that can be assigned in isolation of a linguistic context, but which nonetheless makes a systematic contribution to the meanings of linguistic contexts in which it does feature. So "the present Prime Minister of the United Kingdom" is, strictly speaking, meaningless, but "the present Prime Minister of the United Kingdom is dishonest" is meaningful. Russell does offer arguments for this claim as a thesis regarding definite descriptions in natural language. However, his case is far stronger as an observation about the behavior of certain descriptive constructions within the formal system of his substitutional theory.

The substitutional theory makes a wholesale revision of predicate logic (most notably higher-order predicate logic), to such a dramatic extent that it can seem quite alien on first acquaintance. In place of propositional functions of the sort familiar from predicate logics, Russell introduces constructions which he calls matrices. The simplest kind of matrix is of the form: $p / a$, where ' $p$ ' and ' $a$ ' are understood as wholly unrestricted variables ranging over any entities whatsoever. Russell then introduces a primitive substitution operation, symbolized as $p / a: x$ which can be read as a definite description "the result of replacing $a$ in $p$ by $x^{\prime \prime}$. We then have propositions describing the results of these substitutions of the form " $p / a x$ ! $q$ " which can be read: " $q$ results from the substitution of $a$ in $p$ by $x^{\prime \prime}$.

Although the substitutional theory only had very limited exposure in Russell's published work, ${ }^{17}$ he devoted a great deal of effort to this new system of

${ }^{16}$ Russell is famously rather sloppy in his demarcation of use and mention of symbols when employing this distinction, so this understanding does require us to be charitable with some of the things he says about incomplete symbols. I think most would agree with this interpretation of the concept, however. 17 The theory was first published in the 1906 paper 'On Some Difficulties in the Theory of Transfinite Numbers and Order Types', which had been read before the London Mathematical Society in 1905. The theory (under the name 'noclasses theory') was tentatively suggested without full endorsement alongside alternative responses to the paradoxes in the paper, but by the time of publication, Russell was prepared to add a note, dated $5^{\text {th }}$ February 1906: 'From further investigation I now feel hardly any doubt that the no-classes theory affords the complete solution of all the difficulties stated in the first section of this paper' (Russell 1906a: 164). However, he subsequently withdrew before publication a more elaborate statement of the theory titled 'On the Substitutional 
logic. In manuscripts he developed detailed axiomatizations of the system, proving many important theorems and clearly working towards an attempted demonstration of logicism within the system. For reasons that we will not go into here, that demonstration was not to be completed, and Russell was eventually persuaded to forego substitution as the formal language for Principia Mathematica. ${ }^{18}$ Nonetheless, we can see from his incomplete efforts, why it was that he felt that the justification for theory of types lay in the theory of descriptions. The real benefit of substitution becomes apparent when we see the application that Russell intends for the matrices of the theory: 'The theory which I wish to advocate is that this shadowy symbol $p / a$ represents a class' (Russell 1906b: 170). In other words, the idea behind the theory is that these matrices have all of the formal properties needed of classes. Yet, and this is the key point, they are not themselves entities. Russell defines "class" membership as follows: $x$ is a member of the "class" $p / a$ just in case the substitution of $x$ for $a$ in $p$ results in a true proposition. Notice that neither $p$ nor a must be propositions for the matrix to be well-formed; however, only in the case where $p$ is a proposition, can the "class" be non-empty. Russell's ontology must embrace propositions for the substitutional theory to have a coherent interpretation, but it does not need to embrace classes. Hence the substitutional theory is, in a perfectly clear way, Russell's first no-classes theory. What makes the substitutional theory most impressive, however, is that once we have defined "classes" as derived wholly from matrices of propositions, we effectively gain a theory of logical types for free. This follows immediately from the fact that only entities may be substituted for entities. Not being itself an entity, a matrix cannot be substituted for an entity in another matrix. This immediately blocks any possibility of self-

Theory of Classes and Relations' after it had been accepted by the journal of the same society. He then published his most complete version of the theory in French, under the title 'Les Paradoxes de la Logique', later that year. This was later translated under the name 'On "Insolubilia" and their Solution by Symbolic Logic', and published alongside the other two papers in Russell (1973). 18 It does feature, however, in Russell (1908), although in such a cryptic form as to have gone more or less unnoticed for nearly 70 years. The recovery of the theory began with the publication of Russell (1973). However, it was the publication of Russell's correspondence with Philip Jourdain in Grattan-Guinness (1977) that made the importance of the theory clear. Landini's (1998) is the definitive study of the substitutional theory. 
membership among "classes". If, for example, $p / a$ is a class, then any attempt to predicate self-membership of this class will be simply ungrammatical in the language of substitution. We cannot have matrices of the form $p / a ;(p / a)$ because only an entity can be substituted for $a$ in $p / a \cdot{ }^{19}$ As Russell puts it:

But now ' $x$ is an $x$ ' becomes meaningless, because ' $x$ is an $\alpha$ ' requires that $\alpha$ should be of the form $p / a$, and thus not an entity at all. In this way membership of a class can be defined, and at the same time the contradiction is avoided.

(Russell 1906b: 172).

Russell's theory of types has been the subject of a number of vehement criticisms over the past hundred years. The substitutional theory shows that many of these are unfair. For example, Russell's claim that violations of typetheory are "ungrammatical" or "nonsensical" has been dismissed as mere ad hoc stipulation. But we can see that, within the framework of substitution, that the claim is simply justified. Furthermore, related claims like Whitehead and Russell's insistence that they do not countenance the existence of classes, which seem quite cryptic when presented in Principia, make perfect sense when viewed in the light of the substitutional theory (though, whether Russell and Whitehead are still entitled to maintain the same claim in Principia where substitution has been dropped is another question, of course, which I will not go into here). Most importantly for our interests here, the connection between the theory of descriptions and theory of types is made explicit by the substitutional theory. It is only because matrices are incomplete symbols that they generate type distinctions. This is a remarkable achievement that demonstrates Russell's technical genius. But we should be careful what we conclude from it. Whatever merits it may have for Russell's mathematical logic, it is quite independent of the claim that definite descriptions in natural language are incomplete symbols. To

${ }^{19}$ Russell does allow matrices to be substituted for matrices in "higher-order" matrices. For example, $q /(p / a) ;(r / s)$ is well-formed in the language. But here we understand the substitution as a "dual" substitution of $r$ for $p$ and $s$ for $a$ in $p$. Such matrices as seen here are used as the equivalents of both dyadic relational predicates, and classes of classes in the theory (see Russell 1906b: 176). 
demonstrate that, Russell needs to appeal to raw linguistic data; as we will now see, his attempts to locate such data are far less convincing.

Russell's favoured argument for demonstrating that definite descriptions are meaningless in isolation occurs in a number of places, but the following passage from Principia probably puts the argument in its clearest form:

[I]t can be easily shown that (ix)( $\phi x)$ is always an incomplete symbol. Take, for example, the following proposition: 'Scott is the author of Waverley' ... This proposition expresses an identity; thus if 'the author of Waverley' could be taken as a proper name, and supposed to stand for some object $c$, the proposition would be 'Scott is $c$.' But if $c$ is anyone except Scott, this proposition is false; while if $c$ is Scott, the proposition is 'Scott is Scott', which is trivial, and plainly different from 'Scott is the author of Waverley'. Generalizing, we see that the proposition

$$
a=(i x)(\phi x)
$$

is one which may be true or may be false, but is never merely trivial like $a=$ $a$; whereas, if $(i x)(\phi x)$ were a proper name, $a=(i x)(\phi x)$ would necessarily be either false or the same as the trivial proposition $a=a$. We may express this by saying that $a=(i x)(\phi x)$ is not a value of the propositional function $a=y$, from which it follows that (ix) $(\phi x)$ is not a value of $y$. But since $y$ may be anything, it follows that $(i x)(\phi x)$ is nothing. Hence, since in use it has a meaning, it must be an incomplete symbol.

(PM: 67)

The problem with the argument is that Russell wants it to support a stronger conclusion than it really establishes, namely that definite descriptions are meaningless. The argument seems to support that conclusion because the term 'nothing' in the penultimate sentence is ambiguous. Russell is talking about the range of values of the variable $y$ in the function 'Scott $=y$ ' can take. Now clearly only objects are going to be in this range of values. So what the argument (if it is 
valid) really establishes is that definite descriptions do not contribute objects to propositions. But that is not the same as their being meaningless.

A weaker - and better - conclusion to draw from Russell's argument is that definite descriptions (along with other quantifier expressions) make available a class of object independent propositions. ${ }^{20}$ If we wish, we can put a metaphysical gloss on the distinction between object dependent and object independent propositions by talking in terms of whether or not objects are contained in the propositions as constituents. But this metaphysical gloss is not essential. We can think of object dependent propositions as propositions expressed by sentences whose truth-conditions depend on objects, and objectindependent ones as expressed by sentences whose truth-conditions do not. For example, the proposition that Scott is happy (that is, the meaning of the sentence "Scott is happy") is true just in case the object Scott has the property of being happy, and false just in case the object Scott lacks the property of being happy; while the proposition that the author of Waverley is happy is true just in case one and only one thing authored Waverley and is happy, and false (on the wide scope reading) just in case it is not the case that one and only one thing authored Waverley and is happy. The difference may seem subtle at first, but it is significant. The first proposition depends on Scott for its truth or falsehood; the second does not. The second in fact has precisely the same feature that Frege first identified as distinctive of quantificational propositions - it is best understood as making a claim about the concepts or properties, which we might (using the notation of lambda-abstraction) specify as $\lambda x$ [ $x$ authored Waverley] and $\lambda x[x$ is happy], and its truth depends on features of the instantiation of these concepts, rather than on any object. Frege himself gave the example of the quantificational sentence "All whales are mammals" to make this point:

It is true that at first sight the proposition "All whales are mammals" seems to not be about concepts but about animals; but if we ask which animal then are we speaking of, we are unable to point to any one in particular. Even supposing a whale is before us, our proposition still does

\footnotetext{
${ }^{20}$ See Neale (1990) for detailed elaboration of this point.
} 
not state anything about it ... As a general principle, it is impossible to speak of an object without in some way designating or naming it; but the word "whale" is not the name of any individual creature ... However true it may be that our proposition can only be verified by observing particular animals, that proves nothing as to its content.

(Frege 1884: 60-61

If we are persuaded by the theory of descriptions we should be persuaded that, like all other quantified propositions, descriptive propositions are independent of particular objects in precisely the way that Frege is describing here. In other words, Russell's claim that descriptions are 'incomplete symbols' that are meaningless in isolation, as powerful a notion as that may have been in the context of his mathematical logic, is best replaced by the claim that descriptive propositions are object independent if the theory is to be taken seriously as an account of the meanings of natural language quantifiers.

\section{Conclusion}

There can be no doubt that the theory of descriptions is located at the very core of Russell's philosophy. It impacts dramatically on his metaphysics, his epistemology, and, of course, his mathematical logic. These impacts, however, have led many readers of Russell to mistake the theory itself as a contribution to one, or more, of these areas. Subsequently, they have concluded that the theory was never intended by Russell to be a contribution to the philosophy of language. Russell, on this interpretation, played the leading role in establishing philosophy of language as a core enterprise of twentieth-century analytical philosophy by accident.

Many of Russell's own comments on philosophy and the so-called "linguistic turn" taken in early part of the twentieth century, are easily read as lending support to this interpretation. However, as I have argued at length elsewhere (Stevens 2011), the hostility displayed by Russell towards those who took this turn is not really hostility against philosophers of language in general, 
but against the "ordinary language" philosophers inspired by the Later Wittgenstein, a school of thought dismissed by Russell as 'completely unintelligible' (MPD: 160). Many, perhaps most, contemporary philosophers of language are likely to share Russell's judgement of this school. Furthermore, the naturalistic approach to language adopted by Russell from 1919 onwards, finds many sympathizers among current philosophers of language.

More importantly, as I have demonstrated above, the theory of descriptions itself should not be viewed through a lens distorted by its applications. The theory is only intelligible as a theory of the semantics of natural language quantification. It is this doctrine which lies at the heart of the many ingenious applications Russell put the theory of descriptions to. Far from being disinterested in the philosophy of language, therefore, Russell made it the essential foundation of his most significant philosophical works. ${ }^{21}$

\section{$\underline{\text { References }}$}

Donnellan, K. (1966) 'Reference and Definite Descriptions', Philosophical Review 75: 281-304.

Evans, G. (1982) The Varieties of Reference, Oxford: Oxford University Press.

Frege, G. (1884) The Foundations of Arithmetic, trans. J.L. Austin, Evanston, Ill.: North Western University Press, 1959.

Frege, G. (1892) 'On Sense and Reference' in Beaney, M.(ed.) The Frege Reader, Oxford: Blackwell, 1997.

Grattan-Guinness (1977) Dear Russell-Dear Jourdain, London: Duckworth: 1977. Kaplan, D. (1989) 'Demonstratives' in Almog, Perry and Wettstein, eds., Themes from Kaplan, Oxford: Oxford University Press, 481-563.

King, J. (2007) The Nature and Structure of Content, Oxford: Oxford University Press.

\footnotetext{
${ }^{21}$ I would like to thank Russell Wahl for helpful comments on an earlier draft.
} 
Kripke, S. (1977) 'Speaker's Reference and Semantic Reference', in Kripke (2011).

Kripke, S. (1980) Naming and Necessity, Oxford: Blackwell.

Kripke, S. (2005) 'Russell's Notion of Scope', in Kripke (2011).

Kripke, S. (2011) Philosophical Troubles: Collected Papers Volume 1, Oxford: Oxford University Press.

Landini, G. (1998) Russell's Hidden Substitutional Theory, Oxford: Oxford University Press.

Neale, S. (1990) Descriptions, Cambridge, Massachusetts: MIT Press.

Quine, W.V.O (1948) 'On What There Is', in Quine, From A Logical Point of View, Massachusetts: Harvard University Press, $2^{\text {nd }}$ edition 1961.

Russell, B. (1905a) 'On Fundamentals' in CPBR 4

Russell, B. (1905) 'On Denoting' in LK.

Russell, B. (1906a) 'On Some Difficulties in the Theory of Transfinite Numbers and Order Types', in EA (reprinted in CPBR 5).

Russell, B. (1906b) 'On the Substitutional Theory of Classes and Relations', in EA (reprinted in CPBR 5).

Russell, B. (1906c) 'On "Insolubilia” and their Solution by Symbolic Logic' in EA (reprinted in CPBR 5).

Russell, B. (1918) 'The Philosophy of Logical Atomism' in LK.

Russell, B. (1923) 'Vagueness', Australasian Journal of Philosophy and Psychology Vol. 1, pp. 84-92, reprinted in CPBR 9.

Russell, B. (1992) Selected Letters of Bertrand Russell, Vol. 1, ed. N. Griffin, London: Routledge.

Salmon, N. (1986) Frege's Puzzle, Cambridge, Massachusetts: MIT Press.

Stevens, G (2004) 'From Russell's Paradox to the Theory of Judgement: Wittgenstein and Russell on the Unity of the Proposition', Theoria 2004 (1): 28-61.

Stevens, G. (2003) 'The Truth and Nothing But the Truth, Yet Never the Whole Truth: Frege, Russell and the Analysis of Unities', History and Philosophy of Logic 24: 221-240.

Stevens, G. (2005) The Russellian Origins of Analytical Philosophy, London: Routledge. 
Stevens, G. (2008) 'Russell and the Unity of the Proposition', Philosophy Compass, 3(3): 491-506.

Stevens, G. (2011) The Theory of Descriptions, Basingstoke: Palgrave Macmillan. Strawson, P.F. (1950) 'On Referring', Mind 59: 320-344, reprinted in Strawson, P.F., Logico-Linguistic Papers, London: Methuen 1971. 